\title{
Recovery after Dietary Treatment of an Infant with Features of Tyrosinosis
}

\author{
J. T. HARRIES, J. W. T. SEAKINS, R. S. ERSSER, and JUNE K. LLOYD \\ From the Departments of Child Health and Chemical Pathology, The Hospital for Sick Children, \\ and Institute of Child Health, University of London
}

Tyrosinosis has been recognized with increasing frequency in recent years, and the disease is characterized by cirrhosis of the liver, renal tubular dysfunction, and hypophosphataemic rickets. These features are associated with a disturbance of tyrosine metabolism thought to be due to a deficiency of the enzyme p-hydroxyphenylpyruvic acid oxidase ( $\mathrm{La} \mathrm{Du}, 1967)$; there is hypertyrosinaemia and hyperphenylalaninaemia, and tyrosine and related phenolic acids are excreted in excessive amounts in the urine. In the acute form of the disease, high blood levels of methionine have also been reported. The exact metabolic cause of the hypermethioninaemia is not understood, and this finding has often been associated with a poor prognosis (Halvorsen et al., 1966; Larochelle et al., 1967; Sass-Kortsak et al., 1967a).

Treatment with a low-tyrosine low-phenylalanine diet is usually followed by rapid and marked improvement in renal function, and subsequent healing of rickets (Halvorsen et al., 1966; SassKortsak et al., 1967c), but its effectiveness in preventing the development of hepatic cirrhosis has not yet been established. In all cases so far reported attempts to terminate the dietary treatment have been followed by rapid clinical and biochemical relapse, and it has been assumed that long-term treatment is therefore essential (Fairney et al., 1968; Aronsson et al., 1968).

We here report an infant in whom the diagnosis was made at the age of 5 months, and who had hypermethioninaemia. Dietary treatment resulted in an excellent clinical and biochemical response and it was subsequently possible to reintroduce a normal diet without relapse.

\section{Case Report}

A girl, the youngest of three children, was born at term weighing $3.69 \mathrm{~kg}$. Her mother was English and her father West Indian; there was no family history of jaundice, and subsequent biochemical studies of the

Received September 19, 1968. parents and sibs showed no abnormalities. The pregnancy was complicated by hydramnios, and the birth by moderate asphyxia, but recovery was rapid. Jaudice was noted at the age of 3 days, and persisted; the stools became pale, and slight bleeding occurred from the nose and rectum. On admission to hospital at the age of 6 weeks, in addition to jaundice and hepatomegaly, she had a large head (circumference $40 \mathrm{~cm}$., above the 90th centile), with widely open anterior fontanelle, and she lay in an extended posture; her eyes were 'sun-set' in appearance, and muscle tone was increased. The total serum bilirubin was $5.0 \mathrm{mg} . / 100$ ml. ( $4.6 \mathrm{mg} . / 100 \mathrm{ml}$. conjugated), the urine contained bilirubin, the serum transaminases were raised (GOT 142 units, GPT 130 units), serum alkaline phosphatase was 60 KA units. Her blood group was A Rh positive (mother was $\mathrm{O} R \mathrm{Rh}$ positive with anti-A antibody in the serum). The following investigations gave normal results: Coombs test, $\mathrm{Hb}$, white blood count, platelets, Wassermann reaction, CSF, toxoplasma dye test, viral complement-fixation titres, and urine for cytomegalic inclusion bodies.

A short course of prednisolone was given without improvement; the bleeding was controlled with vitamin K. A laparotomy was performed at the age of 3 months: the liver was enlarged, soft and dark, and the gallbladder was small and collapsed. A cholangiogram showed a normal biliary tree. Liver biopsy showed the changes of 'giant cell hepatitis' but no features of cirrhosis (Dr. A. H. Cameron) (Fig. 1). Jaundice persisted, and the liver gradually became larger and firmer. The neurological features were considered to be secondary to kernikterus. She was discharged at the age of $4 \frac{1}{2}$ months when the family moved to London.

She presented at The Hospital for Sick Children, Great Ormond Street, with food refusal and vomiting, and these symptoms coupled with the social circumstances resulted in her admission at the age of 5 months. She was well nourished (length 75 th centile, weight 50th centile), moderately jaundiced, with abdominal distension and hepatosplenomegaly (liver $2.5 \mathrm{~cm}$. below costal margin, spleen just palpable). The kidneys were not palpably enlarged. The skull circumference was $43 \mathrm{~cm}$. (90th centile), the anterior fontanelle was wide open, and the frontal bones were bossed. She was severely retarded with a Developmental Quotient (DQ) of 20; the muscle tone was increased, 


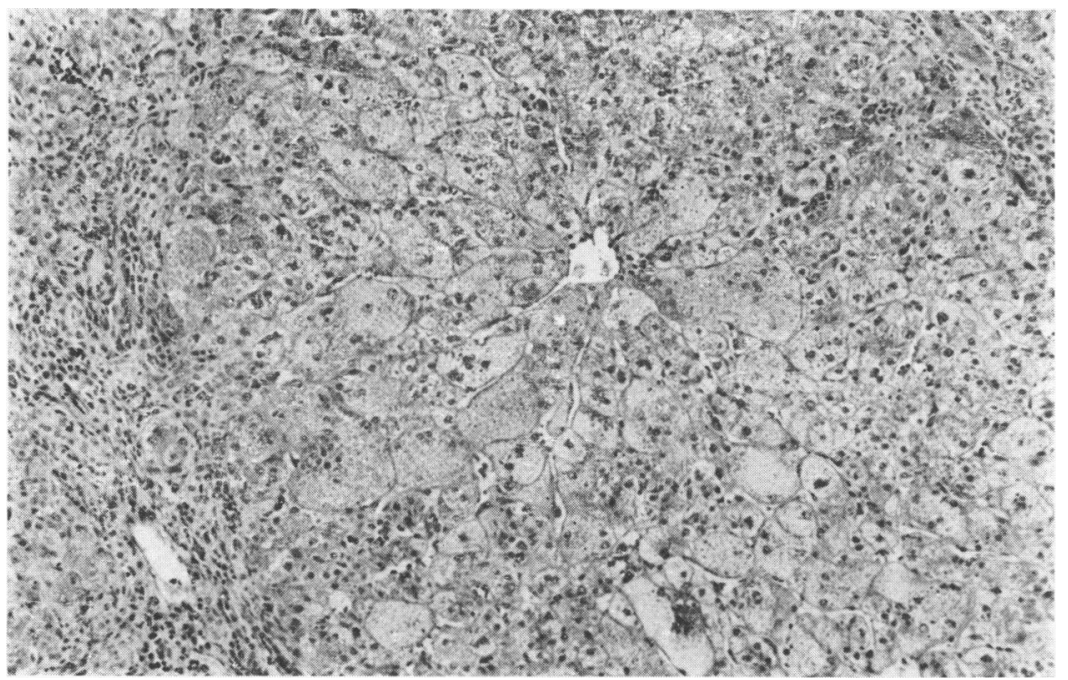

FIG. 1.-Liver, showing giant-cell transformation only. (H. and E. $\times 100$.

the tendon reflexes were brisk and equal, and the blood pressure was $110 / 60 \mathrm{~mm}$. $\mathrm{Hg}$.

Total serum bilirubin $6.3 \mathrm{mg} . / 100 \mathrm{ml}$. $(4.5 \mathrm{mg} . /$ $100 \mathrm{ml}$. conjugated); SGOT 294 units, SGPT 434 units; total serum protein $6.9 \mathrm{~g} . / 100 \mathrm{ml}$., serum albumin (immuno-chemical) $3.5 \mathrm{~g} . / 100 \mathrm{ml} ., \gamma$-globulin increased on electrophoresis; serum cholesterol $122 \mathrm{mg} . / 100 \mathrm{ml}$., triglyceride $37 \mathrm{mg} .100 \mathrm{ml}$, lipoprotein pattern on paper electrophoresis normal; plasma calcium $9.1 \mathrm{mg}$./ $100 \mathrm{ml}$., inorganic phosphorus $3.0 \mathrm{mg} .100 \mathrm{ml}$. (later falling to $2 \cdot 1 \mathrm{mg}$. $/ 100 \mathrm{ml}$.), alkaline phosphatase $64 \mathrm{KA}$ units $/ 100 \mathrm{ml}$., 5-nucleotidase 3 i.u. (normal); plasma sodium $133 \mathrm{mEq} / 1$., potassium $4.8 \mathrm{mEq} / 1$, , chloride

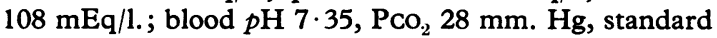
bicarbonate $18 \mathrm{mEq} / 1$.; plasma vitamin A 12 i.u./100 $\mathrm{ml}$; plasma vitamin E. undetectable; autohaemolysis of red blood cells 39\% (normal, 0-5\%); serum copper $106 \mu \mathrm{g} . / 100 \mathrm{ml}$., caeruloplasmin $23.7 \mathrm{mg} .100 \mathrm{ml}$. (normal), iron $46 \mu \mathrm{g} . / 100 \mathrm{ml}$., total iron-binding capacity $277 \mu$ g. $/ 100 \mathrm{ml}$., blood urea $27 \mathrm{mg} . / 100 \mathrm{ml}$., Hb 12.9 g. $/ 100 \mathrm{ml}$; white blood count, platelets, prothrombin time, and erythrocyte sedimentation rate were normal.

Blood levels of tyrosine, phenylalanine, and later methionine were raised. There was generalized aminoaciduria, and in addition the excretion of tyrosine and phenolic acids was greatly increased (details of the amino acid studies are presented separately). The urine also contained bilirubin, but no excess urobilinogen; 24-hour protein concentration was $<10 \mathrm{mg} / 100$ ml., calcium $3.8 \mathrm{mg} . / 100 \mathrm{ml}$. (14 mg. $/ 24 \mathrm{hr}$ ), phosphorus $87 \mathrm{mg} . / 100 \mathrm{ml}$. (326 mg. $/ 24 \mathrm{hr}$.); there was no mellituria, and the urine was sterile. Stercobilin was not detected in the faeces; faecal fat was $30 \mathrm{~g}$./day on an intake of $50 \mathrm{~g}$./day.

$X$-rays showed a fracture of the right seventh rib; skull and long bones were normal; there was no radiological evidence of rickets. An electroencephalogram (Dr. G. Pampiglione) showed a moderate excess of slow components in the posterior temporal regions with some asymmetry between the activities of the frontal lobes.

Dietary management. On admission, feeds consisted of cows' milk and supplied a total daily intake of $391 \mathrm{mg}$. $/ \mathrm{kg}$. phenylalanine, $428 \mathrm{mg} . / \mathrm{kg}$. tyrosine, and $186 \mathrm{mg} . / \mathrm{kg}$. methionine. After diagnosis was established a diet restricted in tyrosine and phenylalanine (Fairney et al., 1968) was started. Initially tyrosine was reduced to $25 \mathrm{mg} . / \mathrm{kg}$. and phenylalanine to $27 \mathrm{mg}$. $/ \mathrm{kg}$. per day. After one week on this regimen, because of raised blood methionine levels, methionine intake was restricted to $75 \mathrm{mg}$. $/ \mathrm{kg}$. per day. The intake of these three amino acids was then adjusted so as to maintain normal blood levels. After the first week only small adjustments were necessary; the range of total daily intake being tyrosine $61-82 \mathrm{mg} . / \mathrm{kg}$., phenylalanine 58-75 mg./kg., methionine $68 / 100 \mathrm{mg} . / \mathrm{kg}$. Requirements did not substantially alter during intercurrent infections. Total daily protein intake varied between 3 and $5 \mathrm{~g} . / \mathrm{kg}$. After 11 months, the dietary intake of the above three amino acids was increased to normal, as described in the special studies of amino acid metabolism. All the dietary changes were well accepted.

Additional vitamin supplements were given in the form of Ketovite tablets and liquid (Paynes and Byrne Ltd.) which supplied 400 i.u. vitamin D daily.

\section{Progress.}

Growth and development. Physical growth was good; her length increased from the 75th centile to just above the 97 th centile, and her weight from the 50 th centile 
Harries, Seakins, Ersser, and Lloyd

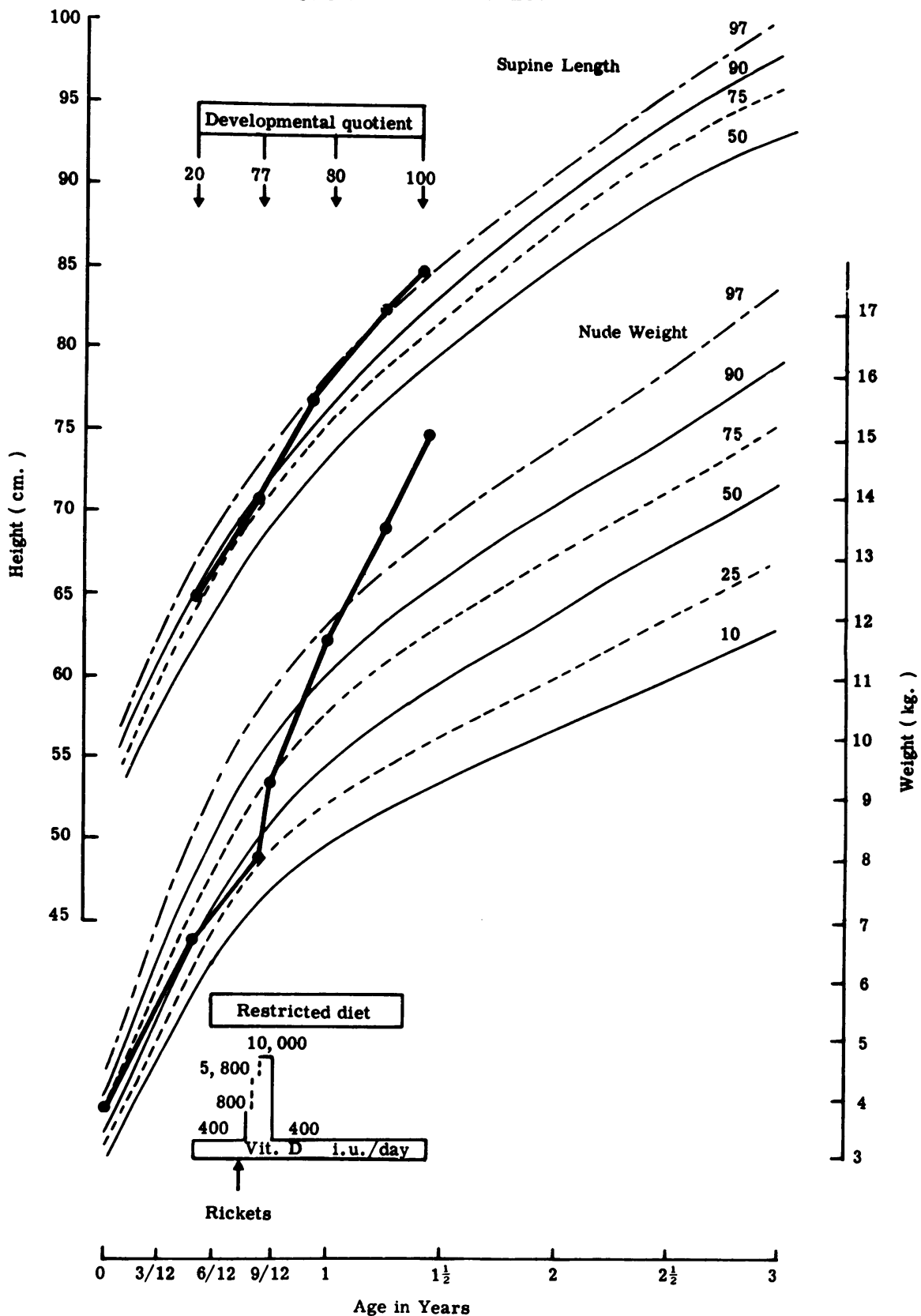

FIG. 2.-Effect of treatment on growth and on developmental quotient.

to above the 97th centile (Fig. 2). At the age of 8 months, the bone age was still retarded, but accelerated to become consistent with chronological age at 15 months. Her neurological development also improved markedly; DQ at 5 months was approximately 20 , and had increased to 100 at 17 months. The signs of spasticity in the limbs disappeared, and serial EEGs showed satisfactory maturation.

Liver function. Within 8 weeks of starting the diet, the serum level of bilirubin became normal, but the 
Ageimonths)

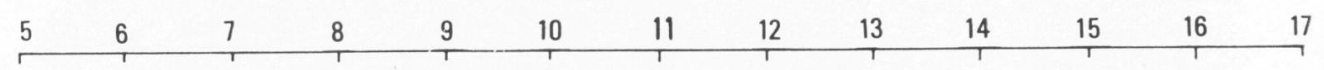

Total Serum Bilirubin(mg. $/ 100 \mathrm{ml}$.)

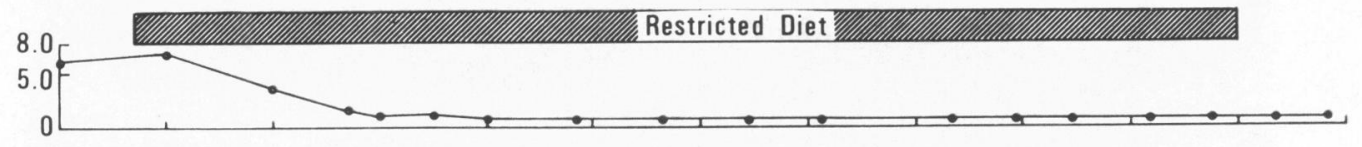

Transaminases( $\mu$.moles Pyruvate $/ 100 \mathrm{ml} . / \mathrm{hr}$ )

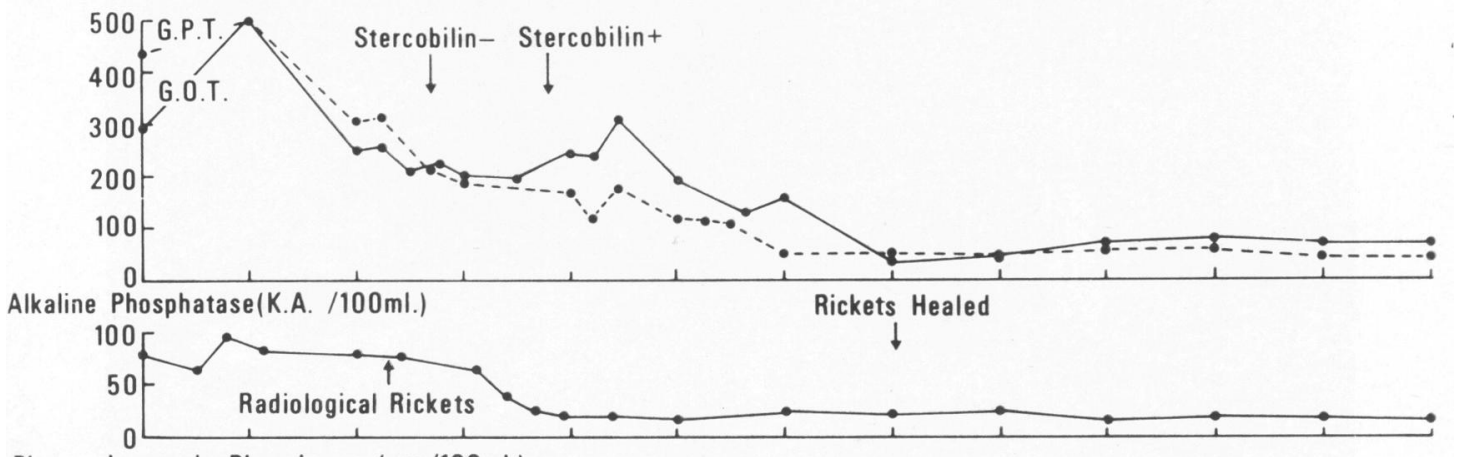

Plasma Inorganic Phosphorus (mg./100ml.)

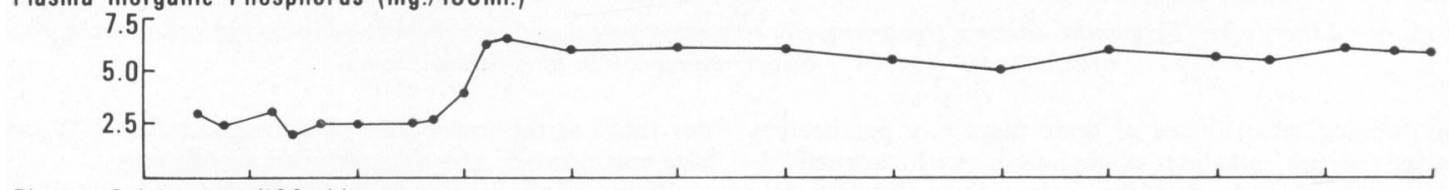

Plasma Calcium(mg./100ml.)

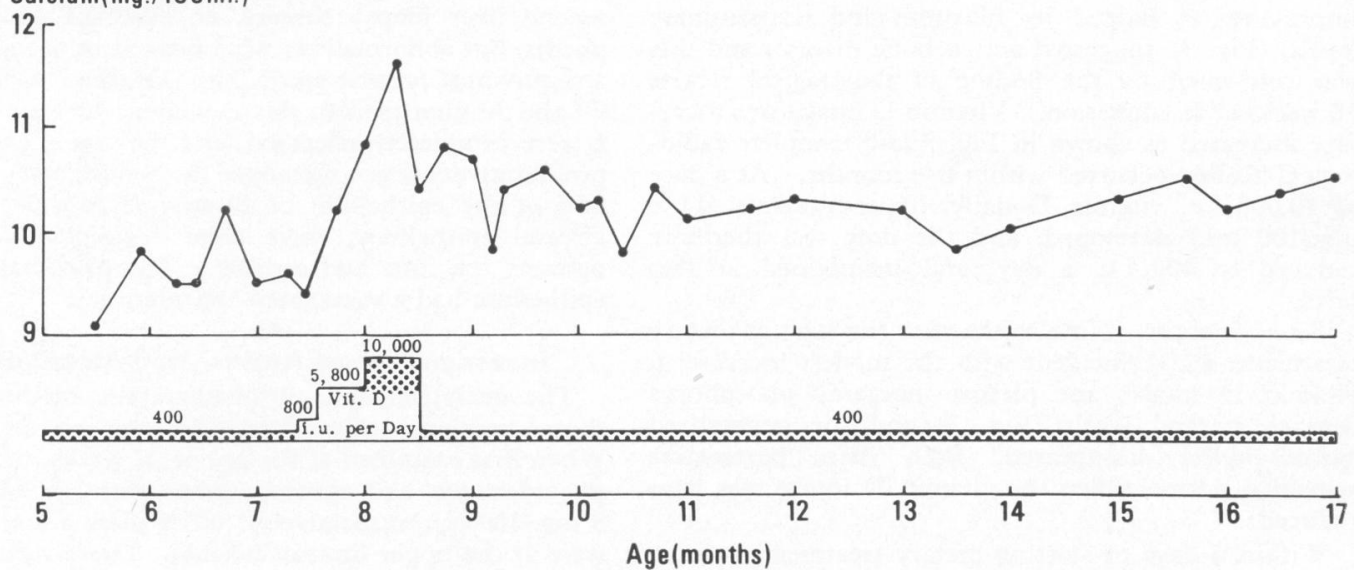

FIG. 3.-Effect of treatment on serum bilirubin, transaminases, alkaline phosphatase, calcium, and phosphorus.

transaminases remained abnormal for a further 13 weeks (Fig. 3). The size of the liver gradually decreased, and the spleen became impalpable. During the period of improving liver function, faecal stercobilin reappeared, and fat excretion declined (12 weeks after treatment mean daily output over 5 days was $4 \cdot 8 \mathrm{~g}$. on an intake of 58-60 g./day). Laparotomy performed $7 \frac{1}{2}$ months after the start of treatment showed that the liver, though still enlarged, had a smooth surface, and normal appearance.

Histology showed normal architecture apart from some increase in portal fibrous tissue and a little intralobular fibrosis (Fig. 4). There was no evidence of regeneration. These appearances may indicate early cirrhosis (Dr. A. E. Claireaux).

Rickets. Though on admission there was no clinical 


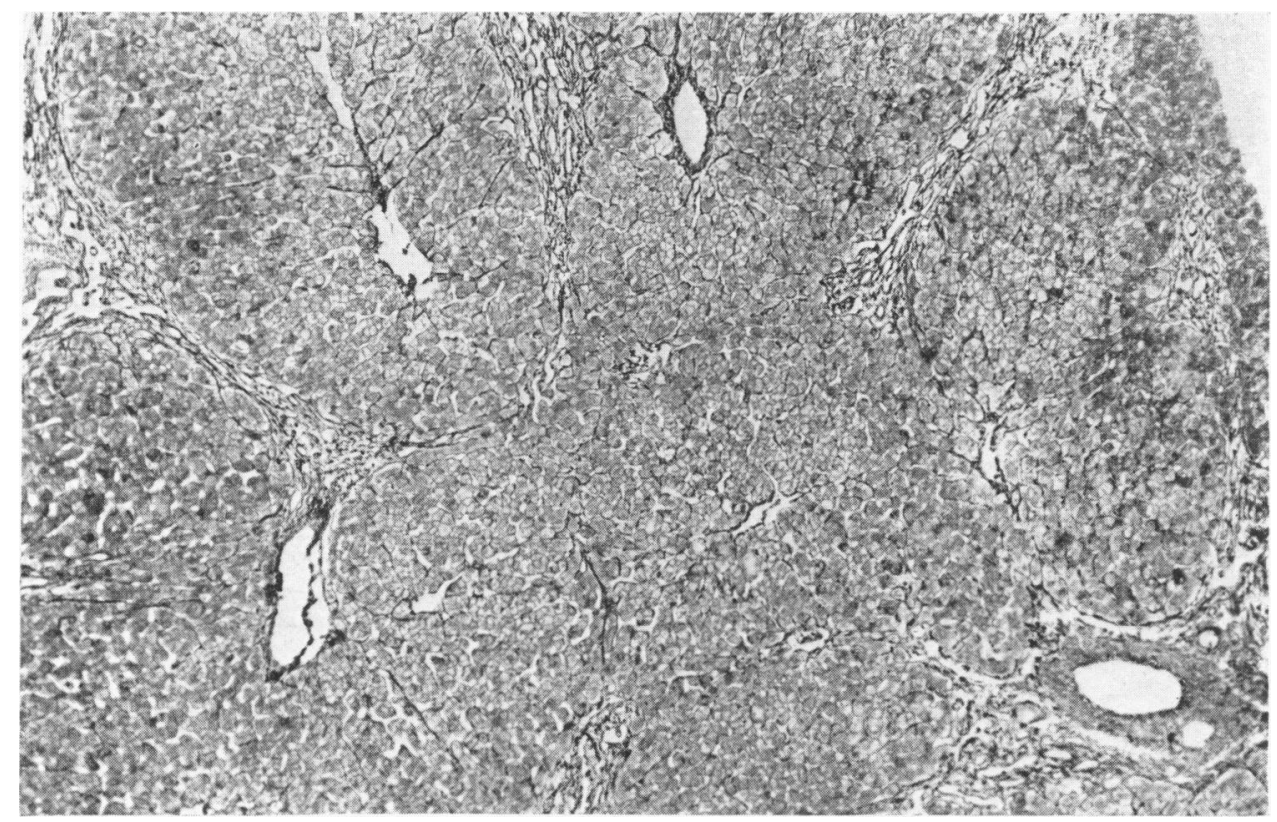

FIG. 4.-Liver, after $7 \frac{1}{2}$ months' dietary treatment, showing some portal and intralobular fibrosis, but otherwise normal architecture. $(\times 40$. Silver impregnation of reticulin fibres. $)$

or radiological evidence of bone disease, a persistently raised serum alkaline phosphatase with normal 5nucleotidase levels at a time when liver function was improving (as judged by bilirubin and transaminase levels) (Fig. 3) suggested active bone disease, and this was confirmed by the finding of radiological rickets 10 weeks after admission. Vitamin $D$ intake was therefore increased as shown in Fig. 3 and complete radiological healing occurred within five months. At a dose of 10,000 i.u. vitamin $\mathrm{D}$ daily, hypercalcaemia (11.6 $\mathrm{mg} . / 100 \mathrm{ml}$.) developed, and the dose was therefore reduced to 400 i.u. a day, and maintained at this level.

Renal function. Nine weeks after the start of dietary treatment, and coincident with the modest increase in vitamin $\mathrm{D}$ intake, the plasma inorganic phosphorus rose to normal levels (Fig. 3) and the generalized aminoaciduria disappeared. Both these parameters remained normal when the vitamin $\mathrm{D}$ intake was later reduced.

Within 4 days of starting dietary treatment, urinary excretion of phosphorus had fallen to $25 \mathrm{mg} . / 100 \mathrm{ml}$. (86 mg. $/ 24 \mathrm{hr}$.) compared with $87 \mathrm{mg} . / 100 \mathrm{ml}$. (326 $\mathrm{mg} . / 24 \mathrm{hr}$.) before therapy. Renal clearance of phosphorus was not estimated before treatment, but after 11 months was normal $(0.2 \mathrm{ml} . / \mathrm{min}$.).

Progress was complicated by urinary infection which responded to appropriate chemotherapy. Because of this finding radiography was undertaken; the cystogram was normal but intravenous pyelography showed blunting of the minor calyces of both kidneys, except for those at the lower pole of the right kidney. Renal size was normal, and dye excretion satisfactory.

Biopsy of the right kidney done on the occasion of the second liver biopsy showed no evidence of pyelonephritis, but abnormalities were present in the glomeruli and proximal tubular epithelium (Dr. B. G. Ockenden). Of the 30 glomeruli in the specimen, 10 were normal, 6 were completely sclerosed, and the rest showed mild proliferative changes, mesangial thickening, and proliferation of the epithelium of Bowman's capsule and the visceral epithelium; there were occasional adhesions between the tufts and capsule. The proximal tubular epithelium had a vacuolated appearance.

\section{Investigations of Amino Acid Metabolism}

The analytical and chromatographic methods were those previously described (Fairney et al., 1968). When first examined at the age of 22 weeks, the plasma phenylalanine and tyrosine levels were raised ( 5 and $8 \mathrm{mg}$./100 ml., respectively); other plasma amino acids were at the upper limit of normal There was a severe generalized aminoaciduria, and the urinary phenolic acid chromatogram showed a gross excretion of phydroxyphenyllactic acid, and to a lesser extent phydroxyphenylacetic and p-hydroxymandelic acids. (Gjessing (1966) has shown that p-hydroxymandelic acid is a breakdown product of p-hydroxyphenylpyruvic acid.) Tests for aromatic keto acids with ferric chloride, 'Phenistix', and 2:4-dinitrophenylhydrazone were equivocal, though paper chromatography of an extract of urine treated with 2:4-dinitro-phenylhydrazine 


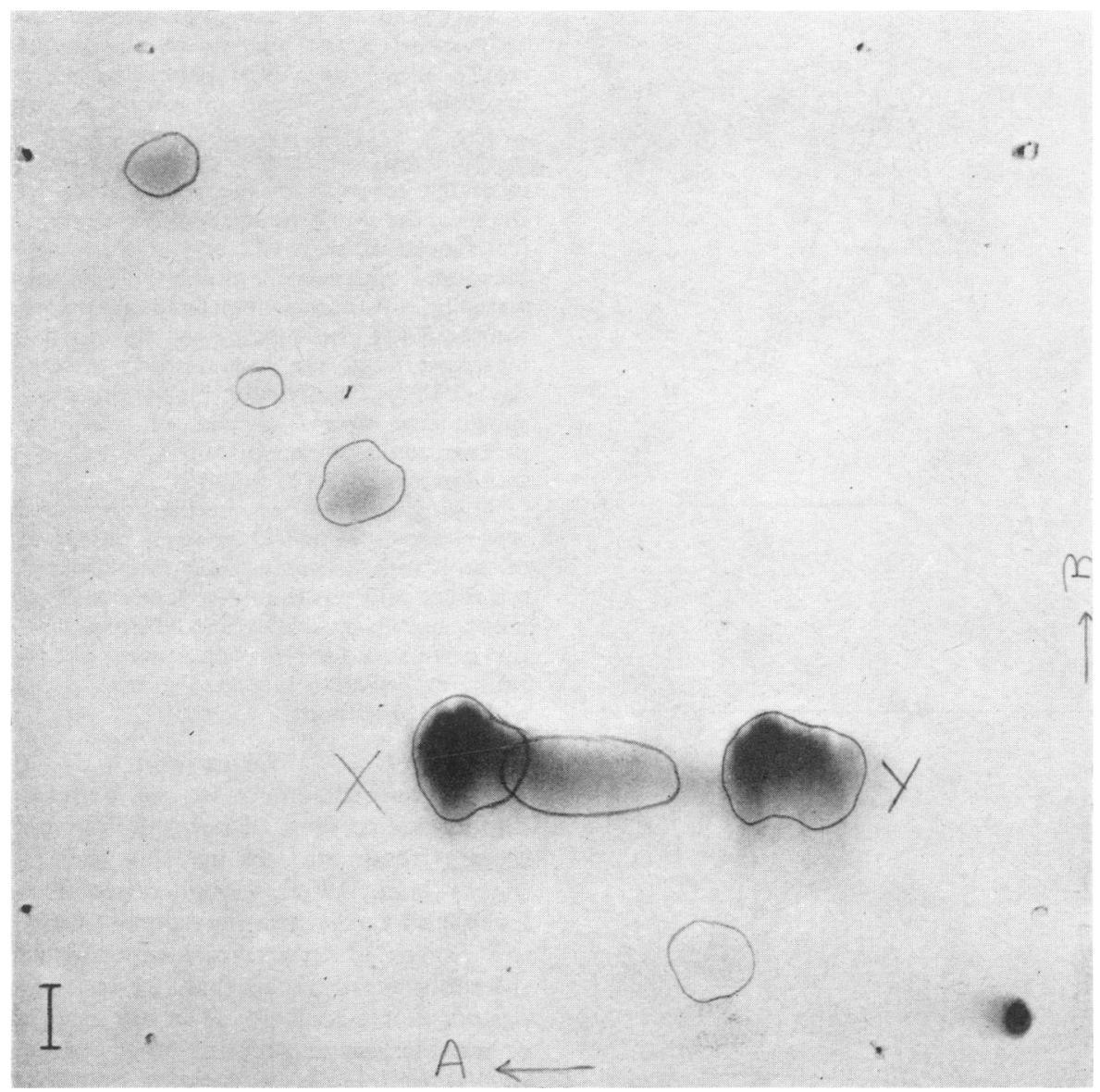

FIG. 5.-Two-dimensional chromatogram of urinary ketoacid 2:4-dinitrophenylhydrazones (equivalent to $0 \cdot 1$ mg. creatinine). Whatman No. SG 81 paper. Solvent A:2-nitropropane/formic acid (99:1); solvent B: benzene/ acetic acid (95:5). $X=2: 4$ DNP of p-hydroxyphenyl-pyruvic acid; $Y=2: 4$ DNP of a-ketoglutaric acid.

(Fig. 5) showed the presence of the hydrazone of phydroxyphenylpyruvic acid but none of the keto acid corresponding to methionine ( $a$-keto- $\gamma$-methiol-nbutyric acid) (Coward and Smith, 1968).

After the institution of a synthetic diet low in phenylalanine and tyrosine, the plasma values of tyrosine and phenylalanine and the urinary phenolic acid chromatogram rapidly became normal, but after 10 days on the diet the plasma methionine was found to be $10 \mathrm{mg}$./ $100 \mathrm{ml}$. (The previous plasma amino acid chromatogram had not been examined with the iodoplatinate reagent for sulphur amino acids, so that a mild hypermethioninaemia of the order of $3-4 \mathrm{mg} . / 100 \mathrm{ml}$. may have been previously missed.) The plasma methionine fell to normal values within 3 days when the methionine intake was restricted. The urinary amino acid pattern slowly became normal over a period of 9 weeks during which ethanolamine was occasionally detected on the chromatogram.
Phenylalanine loading tests. $(0.3 \mathrm{~g} . / \mathrm{kg}$. body weight). The first test was performed at the age of 5 months, a few days before the institution of the diet, and the second test 11 months later after 2 weeks on a synthetic diet containing phenylalanine, tyrosine, and methionine in amounts equivalent to a normal intake. During the second test the child vomited 2 hours after the ingestion of phenylalanine, and we estimate that about $20 \%$ of the load was lost; the plasma values in the two tests cannot therefore be strictly compared, and for this reason the phenylalanine and tyrosine responses in the second test require cautious interpretation. On both occasions the rises in plasma values were higher than the values given by Jervis (1960) for normal adult subjects (Fig. 6). There was, however, a very striking difference between the two sets of urinary phenolic acid chromatograms. During the first test there was a great increase in the excretion of p-hydroxyphenylacetic, -pyruvic and -lactic acids, and p-hydroxy- 


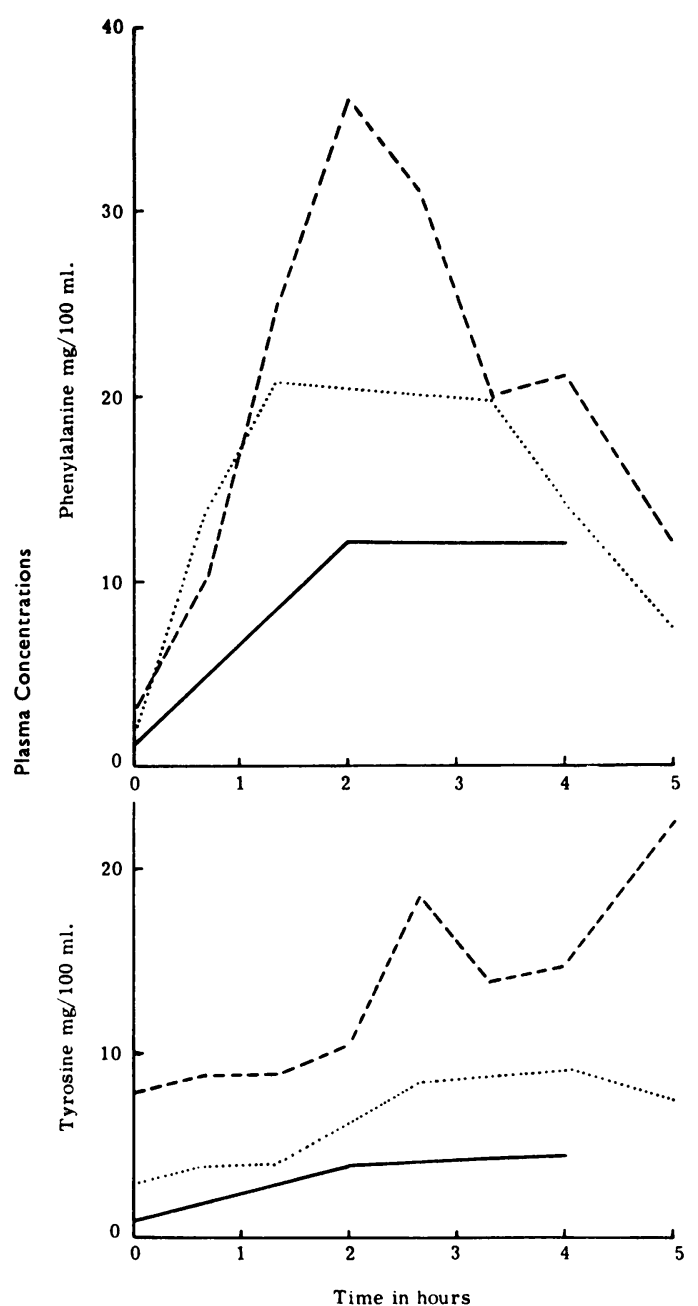

Fig. 6.-Phenylalanine loading tests $(0 \cdot 3 \mathrm{~g} . / \mathrm{kg}$.)

_- - , 1st test aged 5 months;

...., 2nd test aged 16 months;

....., normal adult response (Jervis, 1960).

mandelic acid, and the amounts had not returned to baseline values by the end of 24 hours. No phenylpyruvic or o-hydroxyphenylacetic acids were detected. In contrast, during the second test, the excretion of p-hydroxyphenyl-acetic and -pyruvic acids (the latter detected only by sensitive paper chromatography of the 2:4-dinitrophenylhydrazone) remained within normal limits. No p-hydroxyphenyllactic or p-hydroxymandelic acids were detected, but o-hydroxyphenylacetic was present in all urine specimens passed in the 24 hours following the load, with maximum excretion in the 4-8 hour period. Phenylpyruvic acid was present in the urine passed in the 4-8 hour period (detected by chromatography of 2:4-dinitrophenylhydrazone).
Response to dietary variations. At the age of 15 months, after 43 weeks on the synthetic diet, the child's ability to handle phenylalanine, tyrosine, and methionine, and hence to receive a normal protein intake, was tested according to the scheme outlined in the Table. After two periods (II and IV) in which increased amounts of the amino acids were added to the diet, the synthetic mixture was replaced by 'casilan' (calcium caseinate) (VI), and at this stage the diet was 'flavoured' with suitable amino acids so that the taste was virtually indistinguishable from the previous regimens. Subsequently the amount of flavoured 'casilan' was increased to give a high protein intake $(5 \mathrm{~g}$. $/ \mathrm{kg}$. per day) (VII). Finally, after blood and urine analyses had shown that normal intakes of amino acids and of protein could be adequately handled, a 'normal' diet was introduced at 17 months.

Throughout the test periods, the urinary phenolic acid patterns remained normal, but at the beginning of the first three test periods the plasma phenylalanine, tyrosine, and methionine levels increased slightly, only to become normal within 48 hours (Table). During the period of high protein intake, the whole plasma amino acid pattern increased in intensity but remained within normal limits.

\section{Discussion}

The exact diagnosis in our patient is of great importance in view of her apparent recovery after dietary treatment. In neonatal hypertyrosinaemia (Avery et al., 1967), though raised plasma tyrosine levels and tyrosyluria may persist for many weeks, the degree of hypertyrosinaemia is usually considerably greater than that present in our patient; neither is it associated, as in our case, with hepatic or renal lesions or with any other clinical abnormality. Raised levels of tyrosine, phenylalanine, and methionine may also occur as a secondary phenomenon in liver disease of varying aetiology, and were it not for the renal lesions in our patient this diagnosis would be the most likely. To our knowledge, however, the association of secondary hypertyrosinaemia and hypophosphataemia, phosphaturia, and rickets has not been reported. The presence of hepatic and renal dysfunction (Woolf, 1966) supports a diagnosis of tyrosinosis, though the absence of haematological abnormalities (regarded by B. N. la Du, 1968 personal communication, as an important distinguishing feature) and the subsequent progress, suggest that the disorder may have a different basic defect in our patient. The clinical expression of tyrosinosis is so variable that it is possible, as suggested by Jagenburg (1966), that different diseases may still be represented by this term.

Methioninaemia is not peculiar to tyrosinosis; it is a common manifestation in other forms of acute severe hepatic disease (Kinsell et al., 1949; Scriver 
TABLE

Response to Dietary Variations

\begin{tabular}{|c|c|c|c|c|c|c|c|c|}
\hline \multicolumn{2}{|c|}{ Period and Duration (dy.) } & \multirow[t]{2}{*}{ Type of Diet } & \multicolumn{3}{|c|}{ Intake (mg./kg. per 24 hr.) } & \multicolumn{3}{|c|}{$\begin{array}{l}\text { Plasma (mg. } / 100 \mathrm{ml} .) \\
\text { at End of Each Period }\end{array}$} \\
\hline & & & Phe & Tyr & Met & Phe & Tyr & Met \\
\hline $\mathbf{I}$ & (43 wk.) & Amino acid mixture & $58-75$ & $61-82$ & $68-100$ & 1 & 2 & 0.5 \\
\hline II & 2 & $\begin{array}{l}\text { As in I with added Phe, Tyr, } \\
\text { and Met }\end{array}$ & 265 & 275 & 234 & $\begin{aligned} \star 3 \\
1\end{aligned}$ & $\star 5$ & $\begin{array}{c}\star 2 \\
1\end{array}$ \\
\hline III & 15 & As in I & 67 & 73 & 85 & 1 & 2 & 0.5 \\
\hline IV & 7 & As in II & 265 & 275 & 234 & $\begin{array}{r}\star 3 \\
2\end{array}$ & $\begin{aligned} \star 5 \\
3\end{aligned}$ & $\begin{aligned} \star 2 \\
1\end{aligned}$ \\
\hline $\mathrm{v}$ & 4 & As in $I$ & 67 & 73 & 85 & 1 & 2 & 0.5 \\
\hline VI & 25 & $\begin{array}{l}\text { 'Casilan' with added amino } \\
\text { acids for flavouring }\end{array}$ & 186 & 210 & 158 & $\begin{aligned} \star 2 \\
1\end{aligned}$ & $\star 2$ & $\begin{array}{c}\star 2 \\
0.5\end{array}$ \\
\hline VII & 10 & As in VI but increased 'casilan' & 304 & 278 & 149 & 2 & 4 & 1 \\
\hline VIII & (10 wk.) & Normal diet & \multicolumn{3}{|c|}{ Not measured } & 1 & 2 & 0.5 \\
\hline
\end{tabular}

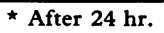

Phe $=$ phenylalanine;

Tyr $=$ tyrosine;

Met $=$ methionine

Davies, and Cullen, 1964) in which it may or may not be associated with an increase of plasma tyrosine (Walshe, 1953). In tyrosinosis it has also been suggested that the methioninaemia occurs as a secondary manifestation of acute liver failure (Gjessing and Halvorsen, 1965), and Scriver, Clow, and Silverberg (1966) found that when hypermethioninaemia was present in tyrosinosis it was accompanied by abnormally raised plasma concentrations of other essential amino acids. Methioninaemia may, however, be directly related to the disturbance in tyrosine metabolism (Gaull, Harris, and Solomon, 1969), and since raised methionine levels may exert a toxic effect, the methionine intake should be restricted in order to keep plasma methionine levels within normal limits. In most reported cases raised plasma methionine levels have in fact been associated with poor liver function and have been present at the time of diagnosis, often indicating a bad prognosis (Halvorsen et al., 1966; Sass-Kortsak et al., 1967a). We are unable to explain the rise in methionine levels in our patient after the introduction of a diet restricted in phenylalanine and tyrosine and at a time when the plasma levels of these two amino acids were normal. Unlike Scriver's patients the other essential amino acids were not raised at any stage.

The effect of dietary treatment on the liver in tyrosinosis is difficult to evaluate (Halvorsen et al., 1966), as reduction in liver size and improvement in tests of liver function have been reported to occur spontaneously with age. In most patients cirrhosis has already been present at the start of treatment, and significant histological improvement after treatment has been observed in only one case (Scriver, Larochelle, and Silverberg, 1967) Our patient has not yet developed the degree of cirrhosis which has hitherto been such a consistent feature of the disease; if this finding is a reflection of the effect of dietary treatment instituted at a pre-cirrhotic stage, it supports the hypothesis that the liver damage is secondary to the biochemical disorder (Scriver, 1967), and suggests that early diagnosis and treatment may modify the sequence of events which ultimately lead to cirrhosis.

The renal lesion in tyrosinosis is characterized by impairment of the tubular reabsorption of phosphorus, and the resultant hypophosphataemia probably plays an important part in the pathogenesis of the rickets. It is well recognized that the phosphaturia may be markedly decreased soon after the start of dietary treatment (Halvorsen, 1967; Gentz et al., 1967; Aronsson et al., 1968), and in our patient this occurred within a few days.

Enlargement of the kidneys has been noted in several instances (Halvorsen et al., 1966; Perry, 1967; Sass-Kortsak et al., 1967b; Aronsson et al., 1968), and reduction in size reported after treatment. It is presumed that the raised levels of plasma tyrosine (or its metabolites) have a direct effect on the renal substance, particularly on the proximal tubule (Perry et al., 1965; Halvorsen et al., 1966) though glomerular lesions have also been described (Aronsson et al., 1968). Immature mice fed high tyrosine diets develop large pale kidneys with proximal tubular changes (Halvorsen and Gjessing, 1966), and rats may develop similar 
abnormalities when fed large amounts of methionine (Klavins, Kinney, and Kaufman, 1963).

We do not know whether the lesions in the glomeruli and proximal tubular epithelium in our patient were present at the time of diagnosis, but it is probable that they were, and they have not yet been completely reversed by treatment.

It is of interest that radiological evidence of rickets did not develop in our patient until after dietary treatment had been started. Possibly impaired vitamin $\mathrm{D}$ and calcium absorption occurred as a result of her steatorrhoea, and aggravated the effects of pre-existing hypophosphataemia. Steatorrhoea in tyrosinosis has been poorly investigated, and though it is generally assumed to be secondary to hepatic cirrhosis, the possibility of a specific intestinal lesion has not been excluded. Though in some cases the rickets has healed on dietary treatment alone, or with small amounts of additional vitamin D (Halvorsen et al., 1966; Aronsson et al., 1968), large doses of vitamin $\mathrm{D}$ may be necessary in addition to dietary treatment (Fairney et al., 1968), and occasionally hypercalcaemia has been induced (Gentz, Jagenburg, aud Zetterström, 1965). In our patient hypercalcaemia occurred after only a modest increase in dosage (10,000 units daily for 2 weeks), and this may have been related to coincident improvement in intestinal absorption. Subsequent maintenance on physiological doses of vitamin D (400 units daily) was sufficient to enable the rickets to heal completely.

Mental retardation has been reported in a few cases (Gentz et al., 1965; Kogut, Shaw, and Donnell, 1967) but its relation to the biochemical abnormality is not clearly established. In a group of 23 children with 'benign neonatal tyrosinaemia' followed up for 43 months, no neurological or developmental abnormalities were found (Partington et al., 1968). The improvement in developmental status which occurred in our patient was striking, but it is not possible to say how much of this can be attributed to the improvement in her general physical condition and the environmental circumstances, and how much to the lowering of plasma amino acid levels.

It has generally been assumed that long-term dietary treatment would be necessary. In one child a normal diet was successfully reintroduced at the age of 22 weeks (Wong, Lambert, and Komrower, 1967); in this patient, a full-term infant, there was persistent hypertyrosinaemia, and hepatomegaly with abnormal liver function tests developed at the age of 7 weeks. Biochemical improvement was achieved by dietary treatment, and relapse initially occurred when the diet was discontinued at 12 weeks. At no time, however, was the serum phosphorus level abnormal, and the subsequent progress led the authors to suggest that a subclinical hepatitis may have caused unusual features in their patient who probably represented an example of 'benign neonatal hypertyrosinaemia' In all cases of tyrosinosis with renal tubular abnormalities where withdrawal of dietary treatment has been attempted, this has been followed by prompt biochemical and clinical relapse (Halvorsen et al., 1966; Aronsson et al., 1968). Why our patient did not relapse on a normal dietary intake of phenylalanine and tyrosine is unknown. Though the response to the second phenylalanine load apparently showed a considerable improvement over the first, the plasma amino acid levels were still higher than those reported for normal (adult) subjects, especially when the loss of some of the load by vomiting is taken into account. Striking differences, however, between the two load tests were seen in the urinary phenolic acid patterns: during the first test, the gross excretion of tyrosine metabolites was consistent with the virtual absence of p-hydroxyphenylpyruvic acid oxidase; during the second test these tyrosine metabolites were virtually absent, indicating efficient further metabolism of tyrosine derived from ingested phenylalanine. Recent studies (summarized by La Du, 1967) have shown that the enzyme p-hydroxyphenylpyruvic acid oxidase also converts phenylpyruvate to o-hydroxyphenylacetate. The presence of phenylpyruvic acid (substrate) and o-hydroxyphenylacetic acid (product) in urine specimens passed during the second phenylalanine load may be taken as further evidence for the near normal functioning of p-hydroxyphenylpyruvic acid oxidase. However, the converse conclusion cannot be drawn from the first phenylalanine loading test, since no phenylpyruvic acid was detected, indicating perhaps additional inactivity of phenylalanine transaminase. Absence of phenylalanine transaminase has been postulated in some forms of neonatal hyperphenylalaninaemia (Buist, 1967).

It appears, therefore, as if either the deficiency of the enzyme p-hydroxyphenylpyruvic acid oxidase and possibly also of phenylalanine transaminase has been temporary, with recovery occurring at some stage after the age of 24 weeks, or that there is a different basic defect in our patient. Menkes and Jervis (1961), in describing an infant with a disorder of tyrosine metabolism who presented with seizures, spasticity, and failure to gain weight, and who responded promptly to restriction of dietary phenylalanine at the age of 4 months, suggested 


\section{Recovery after Dietary Treatment of an Infant with Features of Tyrosinosis}

that the beneficial effect of the diet was due to removal of $p$-hydroxyphenylpyruvic acid oxidase inhibition when the accumulation of p-hydroxyphenylpyruvic acid was decreased. It is possible that a similar mechanism operated in our patient. If dietary treatment has such a beneficial effect, it is obviously important to treat patients who have abnormalities of tyrosine metabolism associated with symptoms, though it is equally important to review the necessity for treatment at regular intervals in order to avoid the unnecessary treatment of children with temporary enzyme defects or other abnormalities. We suggest that any trial of a 'normal diet' should be carried out in the first instance by the addition of amino acids, or suitably flavoured protein, to the restricted diet so that treatment can be resumed, if necessary, without difficulty.

\section{Summary}

A diagnosis of tyrosinosis was made in a 5-monthold child who presented with obstructive jaundice and developmental retardation; she had raised levels of plasma tyrosine, phenylalanine, and methionine; hypophosphataemia, phosphaturia, and a generalized aminoaciduria, together with increased excretion of phenolic acids; and she subsequently developed rickets. On a diet restricted in tyrosine, phenylalanine, and methionine, she made an excellent clinical and biochemical response, and at the age of 17 months ( 1 year after the start of dietary treatment) it was found possible to reintroduce a normal diet.

It is possible that the basic disorder is different from that present in other cases of tyrosinosis.

We thank Dr. W. H. P. Cant for allowing us to publish details of the first hospital admission, Mrs. S. Evans for technical help, and Dr. P. Smith for the chromatogram reproduced in Fig. 5. Treatment would have been impossible without the work of Miss D. M. Francis and her staff in the Dietetic Department, to whom we are most grateful. J. W. T. S. also thanks the Nuffield Foundation and the Joint Research Board of The Hospital for Sick Children and the Institute of Child Health for financial support.

\section{REFERENCES}

Aronsson, S., Fingleson, G., Jagenburg, R., and Palmgren, B. (1968). Long-term dietary treatment of tyrosinosis. $\boldsymbol{f}$. Pediat., $72,620$.

Avery, M. E., Clow, C. L., Menkes, J. R., Ramos, A., Scriver, C. R., Stern, L., and Wasserman, B. P. (1967). Transient tyrosinemia of the newborn: dietary and clinical aspects. Pediatrics, 39, 378.

Buist, N. (1967). In Amino Acid Metabolism and Genetic Variation, p. 117. Ed. by W. L. Nyhan. McGraw-Hill, New York.

Coward, R. F., and Smith, P. (1968). The detection of keto acids in biological fluids by two dimensional paper chromatography of their 2, 4-dinitrophenylhydrazones. f. Chromatog., 33, 508.

Fairney, A., Francis, D., Ersser, R. S., Seakins, J. W. T., and Cottom, D. G. (1968). Diagnosis and treatment of tyrosinosis. Arch. Dis. Childh., 43, 540.

Gaull, G. E., Harris, R. C., and Solomon, G. (1969). Tyrosinosis; biochemical and dietary studies. Amer. F. Dis. Child. In the press.
Gentz, J., Jagenburg, R., and Zetterström, R. (1968). Tyrosinemia. f. Pediat., 66, 670.

_- Lindblad, B., Lindstedt, S., Levy, L., Shasteen, W., and Zetterström, R. (1967). Dietary treatment in tyrosinemia (tyrosinosis). Amer. F. Dis. Child., 113, 31

Gjessing, L. R. (1966). Pyruvic acid metabolism in tyrosinosis. In Symposium on Tyrosinosis, p. 66 . Ed. by L. B. Giessing. Oslo University Press, Oslo.

tyrosinosis. Lancet, $2,1132$.

Halvorsen, S. (1967). Dietary treatment of tyrosinosis. Amer. $\mathcal{F}$. Dis. Child., 113, 38.

- -, and Gjessing, L. R. (1966). Clinical studies of dietary treatment of tyrosinosis. In Symposium on Tyrosinosis, p. 105. Ed. by L. R. Gjessing. Oslo University Press, Oslo.

- -, Pande, H., Løken, A. C., and Gjessing, L.. R. (1966). Tyrosinosis: a study of 6 cases. Arch. Dis. Childh., 41, 238.

Jagenburg, R. (1966). Discussion. In Symposium on Tyrosinosis, p. 120. Ed. by L. B. Gjessing. Oslo University Press, Oslo.

Jervis, G. A. (1960). Detection of heterozygotes for phenylketonuria. Clin. chim. Acta, 5, 471 .

Kinsell, L.. W., Harper, H. A., Giese, G. K., Margen, S., McCallie, D. P., and Hess, J. R. (1949). Studies in methionine metabolism. II fasting plasma methionine levels in normal and hepatopathic individuals in response to daily methionine ingestion. f. clin. Invest., 28, 1439.

Klavins, J. V., Kinney, T. D., and Kaufman, N. (1963). Histopathologic changes in methionine excess. Arch. Paih., 75, 661.

Kogut, M. D., Shaw, K. N., and Donnell, G. N. (1967). Tyrosinosis. Amer. F. Dis. Child., 113, 47.

La Du, B. N. (1967). The enzymatic deficiency in tyrosinemia. ibid., 113, 54.

Larochelle, J., Mortezai, A., Belanger, M., Tremblay, M., Claveau, J. C., and Aubin, G. (1967). Experience with 37 infants with tyrosinemia. Canad. med. Ass. 7., 97, 1051.

Menkes, J. H., and Jervis, G. A. (1961). Developmental retardation associated with an abnormality in tyrosine metabolism. Report of a case. Pediatrics, 28, 399.

Partington, M. W., Delahaye, D. J., Masotti, R. E., Read, J. H., and Roberts, B. (1968). Neonatal tyrosinaemia: a follow-up study. Arch. Dis. Childh., 43, 195.

Perry, T. L. (1967). Tyrosinemia associated with hypermethioninemia and islet cell hyperplasia. Canad. med. Ass. F., 97, 1067.

—-, Hardwick, D. F., Dixon, G. H., Dolman, C. L., and Hansen, S. (1965). Hypermethioninemia: a metabolic discrder associated with cirrhosis, islet cell hyperplasia, and renal tubular degeneration. Pediatrics, 36, 236.

Sass-Kortsak, A., Ficici, S., Paunier, L., Kooh, S. W., Fraser, D., and Jackson, S. H. (1967a). Clinical and biochemical study of three patients with tyrosyluria. Canad. med. Ass. F., 97, 1056. $-,-\ldots,--,--, \ldots$, and $-(1967 \mathrm{~b})$. Secondary metabolic derangements in patients with tyrosyluria. Canad. med. Ass. F., 97, 1079.

,,,,$--------\longrightarrow$, and - (1967c). Observations on treatment in patients with tyrosyluria. ibid., 97, 1089.

Scriver, C. R. (1967). The phenotypic manifestations of hereditary tyrosinemia and tyrosyluria: a hypothesis. ibid., $\mathbf{9 7 ,} 1073$.

—, Clow, C. L., and Silverberg, M. (1966). Hypermethioninaemia in acute tyrosinosis. Lancet, $1,153$.

- D, Davies, E., and Cullen, A. M. (1964). Application of a simple micromethod to the screening of plasma for a variety of aminoacidopathies. ibid., 2, 230.

-, Larochelle, J., and Silverberg, M. (1967). Hereditary tyrosinemia and tyrosyluria in a French Canadian geographic isolate. Amer. F. Dis. Child., 113, 41.

Walshe, J. M. (1953). Disturbances of aminoacid metabolism following liver injury: a study by means of paper chromatography. Quart. F. Med., 22, 483.

Wong, P. W. K., Lambert, A. M., and Komrower, G. M. (1967). Tyrosinemia and tyrosyluria in infancy. Develop. Med. Child Neurol., 9, 551.

Woolf, L. I. (1966). Inborn hepato-renal dysfunction. In Renal Tubular Dysfunction, p. 171. C. C. Thomas, Springfield, Illinois.

Correspondence to: Dr. June K. Lloyd, Institute of Child Health, 30 Guilford St., London W.C.1. 